\title{
Method for the physical characterization of substrates using centrifugation
}

\author{
Eduarda Demari Avrella ${ }^{1 *} \oplus$, Luciana Pinto Paim ${ }^{1}$, Aquélis Armiliato Emer ${ }^{1 \oplus}$, Lilia Beatriz Vence ${ }^{2} \odot$, Claudimar Sidnei Fior ${ }^{1}$
}

'Universidade Federal do Rio Grande do Sul/Faculdade de Agronomia - Depto. de Horticultura e Silvicultura, Av. Bento Gonçalves, 7712 - Porto Alegre, RS - Brasil.

2Universidad de Buenos Aires/Facultad de Agronomia, Av. San Martín 4453, C1417 CABA - Buenos Aires - Argentina. ${ }^{*}$ Corresponding author <dudademari@hotmail.com>

Edited by: Mohammad Valipour

Received April 16, 2021

Accepted July 15, 2021
ABSTRACT: The characterization of substrate properties supports the correct choice of components and directs management decisions in container cultivation. There are several systems of analysis, however, the routine procedures to determine the water retention curve (WRC) are time consuming and inaccurate. This study proposed a reproducible, less timeconsuming, and easy to perform method for physical characterization of substrates. We used Sphagnum peat, coconut powder, carbonized rice husk, expanded vermiculite, and expanded clay in isolation. The WRC was obtained at tensions $0,10,50$, and $100 \mathrm{hPa}$ using the method of Büchner funnel, the European standard (CEN-EN13041), and by the centrifugation method of samples. In centrifugation, tensions were simulated by combining the angular velocity, sample height, and radius measured from the sample outermost point to the central point of the centrifuge. Three rotations were applied (230; 520 and $730 \mathrm{rpm}$ ), testing the centrifugation time for each tension and then the volumetric water content was compared between the methods. The results showed a positive correlation $(p<0.001)$ between the centrifugation and standard methods, considering that the centrifugation time required for moisture stabilization varied according to the material analyzed and the tension applied. However, the time required to obtain a report was reduced by half. Sample centrifugation is a promising method, ensuring that the tensile force actually acts on the entire sample to determine the water retention curve of the substrate also reducing the duration of the analyses.

Keywords: Sphagnum peat, substrate analysis, analysis methods, expanded clay, water retention curve

\section{Introduction}

Substrates are important in seedling production; therefore, experiments using new components and studies of analysis methods have been carried out for decades. Many of these experiments provide information on physical characteristics (Verdonck et al., 1978; Fonteno et al., 1981; Bunt, 1983; Wallach et al., 1992; Wever and van Winkel, 2004; Caron et al., 2005; Fermino and Kämpf, 2005; Vence, 2012; Zorzeto et al., 2014). Several analysis systems have been used; however, in general, there is no consensus about the most appropriate method to be used. According to the Brazilian legislation (Normative Instruction No. 17 of May 21, 2007), the water retention curve (WRC) is determined by the Tension Table Method in which the volumetric humidity is obtained through the percentage of water retained at $10 \mathrm{hPa}$. Nevertheless, choosing substrates based on other characteristics that are not provided in this Normative Instruction is essential to support the choice for each demand, such as available and remaining water. These characteristics are performed through different methods, but the results frequently show variations, causing divergence between reports.

We hypothesize that it is possible to analyze the WRC more precisely and at a shorter time by simulating tensions that determine water extraction in a centrifugation system, using equipment to control other variables, including environmental variables, such as temperature and relative humidity. Therefore, this study proposed a method for physical characterization of substrates that is reproducible and easy to perform, allowing to determine the WRC in less time, improving routine procedures of laboratory analyses and reducing the time to obtain reports.

\section{Materials and Methods}

In this study, we used Sphagnum peat, coconut powder, carbonized rice husk, expanded vermiculite, and expanded clay in isolation. These components were chosen because of their different origins (organic and mineral) with heterogeneous compositions, different shapes, and particle sizes (Figure 1), consequently generating formulations with different physical characteristics. In addition, these materials are widely

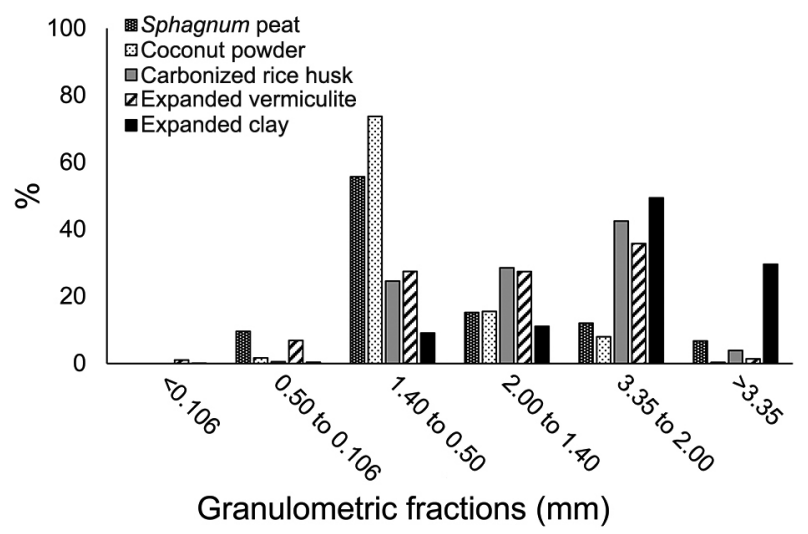

Figure 1 - Particle size of Sphagnum peat, coconut powder, carbonized rice husk, expanded vermiculite, and clay. 
used as substrates for seedling production in various cultivation systems, which are not only easy to be purchased but available throughout the year.

The proportional distribution of particle size was determined using $100 \mathrm{~g}$ samples of air-dried material for $24 \mathrm{~h}$, where the samples were passed through a sieving system $(3.35 ; 2.00 ; 1.40 ; 0.50$ and $0.106 \mathrm{~mm}$ mesh) under manual shaking for $2 \mathrm{~min}$. The fractions retained in each sieve were weighed and the percentages calculated based on the total mass of samples. The substrates were subjected to physical characterization by determining the density on a wet and dry basis using the self-compacting method (Hoffmann, 1970). Total porosity, aeration space, water holding capacity (WHC) at $10 \mathrm{hPa}$, available water, readily available water, buffering water, and remaining water were determined at $0,10,50$ and $100 \mathrm{hPa}$, using three methods of analysis.

As experimental variables, the method described by the European Standardization Committee (CEN), based on the EN13041 standard (CEN, 1999), and the method that uses Büchner funnel were used according to the principles of De Boodt and Verdonck (1972). Besides, the method proposed here as an alternative was used to determine the volumetric water content of substrates by centrifuging the samples. This hypothesis was based on studies already carried out with soils, where tensions are simulated by combining the angular velocity, sample height, and the radius measured from the outermost point of the sample to the central point of the centrifugation (Silva and Azevedo, 2001).

\section{CEN-EN13041 normative-based method}

The method CEN-EN13041 is based on the European standard EN-13041:1999, which simultaneously determines dry density, WHC, total porosity, aeration space, readily available water, buffering water, and remaining water. In this method, sand beds are used as tension devices.

Sand beds with dimensions of $50 \mathrm{~cm} \times 35 \mathrm{~cm}$ $\times 30 \mathrm{~cm}$ were used. First, the samples were placed in cylinders (capacity of $2 \mathrm{~L}$ ) sealed at their base with nylon fabric (voile type), and kept with water up to 1 $\mathrm{cm}$ less than its upper edge, for $24 \mathrm{~h}$. After, they were placed to tensioning in a sand bed at $50 \mathrm{hPa}$ until the moisture balance to standardize the initial humidity of the samples. The use of these materials allowed filling sets of two overlapping cylinders of $5 \mathrm{~cm}$ in height and $10 \mathrm{~cm}$ in diameter, which remained in water again for 24 $\mathrm{h}$ and then subjected to a tension of $10 \mathrm{hPa}$.

Once the equilibrium was reached (when the water was drained from the device column) at a tension of $10 \mathrm{hPa}$, the cylinders were removed from the sand bed, eliminating the upper cylinder and then only the mass of the lower cylinder was determined (volume 388 $\mathrm{cm}^{3}$ cylinder), obtaining the mass of the materials after tensioning at $10 \mathrm{hPa}$. Then the cylinders returned to the sand bed where they were subjected to a tension of 50 $\mathrm{hPa}$, remaining in this condition until they reached an equilibrium. Next, the cylinders were weighed again. This same procedure was carried out with the cylinders at the tension adjusted to $100 \mathrm{hPa}$ and immediately after the samples were placed in an oven at $105 \pm 3{ }^{\circ} \mathrm{C}$, where they remained until constant mass.

\section{The Büchner-funnel method}

This experiment used glass-funnels $(23 \mathrm{~cm}$ in diameter) with a porous plate, where the tension was produced by a system of communicating vessels according to the height of the drainage point of a water column in relation to the central point of the sample.

The samples were analyzed in metallic cylinders with a volume of $381.05 \mathrm{~cm}^{3}$ (stainless steel rings 1.50 $\mathrm{mm}$ thick, $5.0 \mathrm{~cm}$ high, and $9.85 \mathrm{~cm}$ internal diameter). Therefore, the bottom of the cylinders was sealed with voile fabric and fastened with a rubber tie. Afterward, the cylinders were filled with different materials and the amount was calculated from their wet density, that is, the amount of material used to fill the cylinders in each sample was defined using the mass of each material necessary to fill the respective cylinder, according to its density.

Next, the cylinders were placed with water up to $2 / 3$ of its height for $24 \mathrm{~h}$. Afterward, the procedures to obtain the water volume in the samples corresponding to the points $0,10,50$, and $100 \mathrm{hPa}$ of tension followed the flowchart in Figure 2.

\section{Alternative method: sample centrifugation}

This method used the Eppendorf model 5804R centrifuge with a substrate sample length of $4.5 \mathrm{~cm}$ and a radius measured from the outermost point of the sample to the central point of the 9-cm centrifugation.

The samples were placed in cylinders with a polypropylene lid on the top and a sintered glass plate (porosity P3 - 16 to 40 microns) at the base (allowing free water drainage, but retaining the sample particles). To cover the base, a glass collector for the drained water was attached to the cylinder. The sets, cylinders, and collectors were coupled to a rigid polypropylene structure inside the centrifuge, which kept the samples in an upright position, when the centrifuge rotor was not activated, and gradually parallel to the direction of gravity according to the speed increase of centrifugation to ensure that the centrifugal force always acted towards the cylinder bottom.

To define the number of revolutions per minute $(\mathrm{rpm})$, the angular velocity was calculated in rpm for each tension $(10 ; 50$ and $100 \mathrm{hPa})$, based on the equations described by Silva and Azevedo (2001). Thus, the following numbers of revolutions per minute were reached: 230, 520, and $730 \mathrm{rpm}$, which correspond to tensions 10,50 , and $100 \mathrm{hPa}$, respectively. 


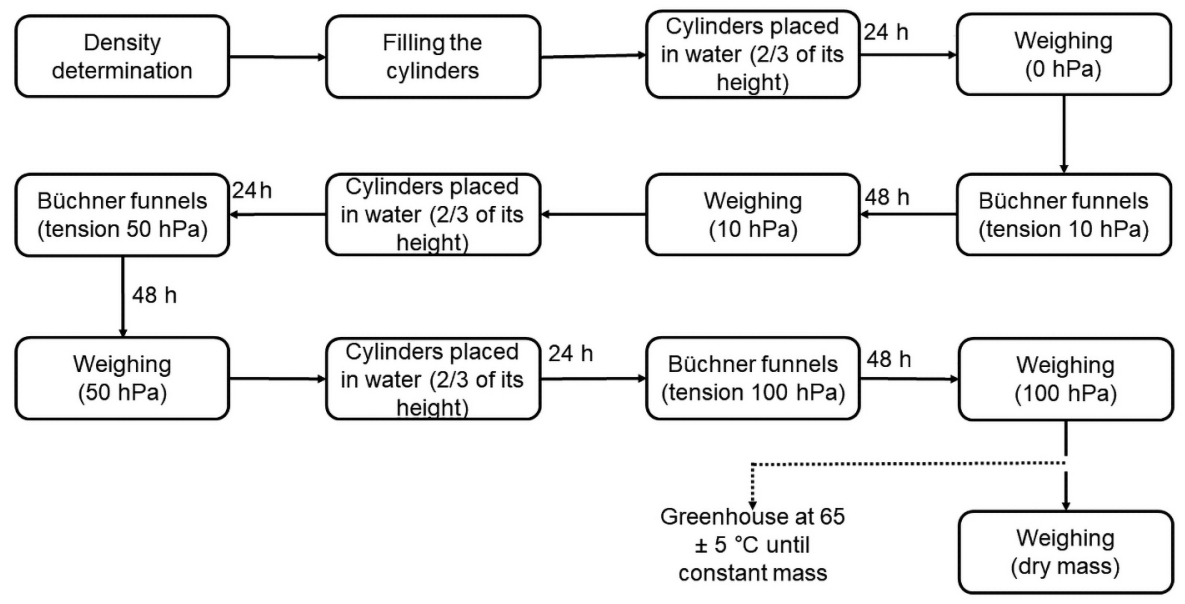

Figure 2 - Flow-chart of the procedures to obtain the water content in the samples after 0, 10, 50, and $100 \mathrm{hPa}$ tensioning using the Büchnerfunnel method.

To determine the necessary centrifugation time to achieve the moisture balance of the samples, centrifugation time at $15,30,60,120,180,240,300,360$, 420,480 , and 540 min was tested for each rotation and for each substrate.

In each test, a set of cylinders composed of six subunits was used, which individually presented 60.96 $\mathrm{cm}^{3}$, totaling a sample volume of $365.76 \mathrm{~cm}^{3}$. The amount of material per cylinder was calculated from their wet density (Hoffmann, 1970). After filling with the materials, the cylinders were left for $24 \mathrm{~h}$ with water up to $2 / 3$ of their height and after they were removed from the water, immediately obtaining the weight corresponding to $0 \mathrm{hPa}$, and then placed in the support of rigid plastic structure attached to the centrifugation plate rotor.

After the period in water, the cylinders were subjected to different centrifugation times in which the water content in the sample was quantified through weighing after each period assessed. Once the equilibrium was reached, with the reduction in water mass between the last three weighing events was less than $1 \%$ of the accumulated volume of extracted water, the samples were taken to the oven at $65 \pm 5{ }^{\circ} \mathrm{C}$ until constant mass to establish the water content that remained in the substrate after centrifugation at each tension applied.

\section{Comparison among the method analysis}

The data on the volumetric water content at $0,10,50$, and, $100 \mathrm{hPa}$ and the parameter values, which are part of the WRC of substrates obtained in the centrifugation method, were compared with the results obtained from the two methods previously mentioned.

In addition, a comparison was made between the time required to obtain a report on the physical characterization of substrates using the two methods considered standard (1 - European, CEN-EN13041; and 2 - Büchner funnel) with the alternative method of sample centrifugation.
The studies were carried out to compare the three methods of analysis and five materials used as substrates (Sphagnum peat, coconut powder, carbonized rice husk, expanded vermiculite, and expanded clayl performed in quadruplicates, that is, four replicates per sample for each material.

The data were submitted to the KolmogorovSmirnov and Bartlett tests to observe the normality and homogeneity of variances, respectively. After meeting these assumptions, the data were submitted to analysis of variance (ANOVA) at $5 \%$ probability of error. Then, in case of significance in the ANOVA for the centrifugation time, the data were submitted to exponential regression and linear regression analysis. In the study of the methods, the means were compared by Fisher's Least Significant Difference (LSD) test and, in addition, the Pearson's Correlation analysis was performed. For all the analyses performed, the software Costat 6.4 and SigmaPlot 11.0 was used.

\section{Results and Discussion}

\section{Centrifugation time assessment}

The results obtained from the exponential regression of the volumetric water content $\left(\mathrm{cm}^{3} \mathrm{~cm}^{3}\right)$ retained in the materials after the centrifugation time showed an inflection point close to $30 \mathrm{~min}$ for all substrates assessed. This indicates a tendency towards moisture balance after $30 \mathrm{~min}$ of centrifugation for each angular speed, despite water loss at each new centrifugation period. According to the linear analysis, such observation allowed to achieve the exact moisture stabilization point at angular velocities equivalent to 10,50 , and $100 \mathrm{hPa}$.

Therefore, linear regressions were adjusted between three consecutive centrifugation times for each material at each assessed angular speed. When the coefficient of determination $\left(\mathrm{R}^{2}\right)$ was greater than or equal to 0.97 , the recommended equilibrium condition 
was considered satisfied, that is, centrifugation time higher than these values did not extract significant water amounts from the sample.

The centrifugation time required to extract the available water at a particular angular speed varied between the materials. For Sphagnum peat, the linear adjustment was obtained between 120 and 240 min of centrifugation for the tension point of $10 \mathrm{hPa}$. Whereas the recommended determination coefficient was reached between 60 and $180 \mathrm{~min}$ for tension points 50 and 100 hPa (Table 1). Thus, for this particular component, 240 min of centrifugation are necessary for an angular speed equivalent to $10 \mathrm{hPa}$ of tension and 180 min for speeds corresponding to points 50 and $100 \mathrm{hPa}$.

Table 1 - Linear regressions and coefficient of determination $\left(R^{2}\right)$ calculated for an interval of three centrifugation times, used to determine the time required to extract all available water at a given tension for the Sphagnum peat, coconut powder, carbonized rice husk, expanded vermiculite, and expanded clay.

\begin{tabular}{|c|c|c|c|c|c|c|}
\hline \multirow{2}{*}{ Time (min) } & \multicolumn{2}{|l|}{$10 \mathrm{hPa}$} & \multicolumn{2}{|l|}{$50 \mathrm{hPa}$} & \multicolumn{2}{|l|}{$100 \mathrm{hPa}$} \\
\hline & Equation & $\mathrm{R}^{2}$ & Equation & $\mathrm{R}^{2}$ & Equation & $\mathrm{R}^{2}$ \\
\hline & \multicolumn{6}{|c|}{ Sphagnum peat } \\
\hline 15 to 60 & $y=622.95-0.4694 x$ & 0.94 & $y=544.55-1.1429 x$ & 0.72 & $y=493.72-0.5502 x$ & 0.71 \\
\hline 30 to 120 & $y=610.52-0.2085 x$ & 0.96 & $y=493.45-0.1324 x$ & 0.81 & $y=469.45-0.0736 x$ & 0.90 \\
\hline 60 to 180 & $y=601.96-0.1166 x$ & 0.96 & $y=485.75-0.0593 x$ & 0.99 & $y=465.57-0.034 x$ & 0.97 \\
\hline 120 to 240 & $y=594.89-0.0724 x$ & $0.99 *$ & $y=483.95-0.0463 x$ & 0.97 & $y=463.04-0.0175 x$ & 0.97 \\
\hline 180 to 300 & $y=598.85-0.0922 x$ & 0.98 & - & - & - & - \\
\hline 240 to 360 & $y=598.25-0.0883 x$ & 0.98 & - & - & - & - \\
\hline 300 to 420 & $y=587.82-0.0573 x$ & 0.99 & - & - & - & - \\
\hline \multirow[t]{2}{*}{360 to 480} & $y=583.41-0.046 x$ & 0.99 & - & - & - & - \\
\hline & \multicolumn{6}{|c|}{ Coconut powder } \\
\hline 15 to 60 & $y=623.15-0.5536 x$ & 0.92 & $y=525.19-1.2561 x$ & 0.71 & $y=480.79-0.6908 x$ & 0.70 \\
\hline 30 to 120 & $y=606.37-0.2024 x$ & 0.93 & $y=467.82-0.1221 x$ & 0.74 & $y=449.94-0.0856 x$ & 0.89 \\
\hline 60 to 180 & $y=600.58-0.1498 x$ & 0.99 & $y=458.56-0.0321 x$ & 0.98 & $y=445.30-0.0386 x$ & 0.97 \\
\hline 180 to 300 & $y=600.01-0.147 x$ & 0.99 & - & - & - & - \\
\hline 240 to 360 & $y=595.97-0.1309 x$ & 0.99 & - & - & - & - \\
\hline 300 to 420 & $y=586.09-0.1015 x$ & 0.99 & - & - & - & - \\
\hline 360 to 480 & $y=582.5-0.0924 x$ & 0.99 & - & - & - & - \\
\hline \multirow[t]{2}{*}{420 to 540} & $y=573.29-0.0716 x$ & 0.98 & - & - & - & - \\
\hline & \multicolumn{6}{|c|}{ Carbonized rice husk } \\
\hline 15 to 60 & $y=623.89-0.5632 x$ & 0.76 & $y=529.57-1.7026 x$ & 0.70 & $y=470.28-0.7542 x$ & 0.65 \\
\hline 30 to 120 & $y=613.06-0.3978 x$ & 0.94 & $y=450.67-0.1488 x$ & 0.74 & $y=434.57-0.0623 x$ & 0.91 \\
\hline 60 to 180 & $y=609.45-0.3271 x$ & 0.93 & $y=439.38-0.0395 x$ & 0.99 & $y=431.48-0.0309 x$ & 0.98 \\
\hline 120 to 240 & $y=594.80-0.2443 x$ & 0.97 & $y=437.58-0.0277 x$ & 0.99 & - & - \\
\hline 180 to 300 & $y=593.66-0.2316 x$ & 0.96 & - & - & - & - \\
\hline 240 to 360 & $y=570.10-0.1473 x$ & 0.99 & - & - & - & - \\
\hline 300 to 420 & $y=574.35-0.1607 x$ & 0.99 & - & - & - & - \\
\hline 360 to 480 & $y=574.47-0.1603 x$ & 0.99 & - & - & - & - \\
\hline 15 to 60 & $y=617.31-0.3763 x$ & 0.95 & $y=566.9-0.7011 x$ & 0.66 & $y=531.83-0.2019 x$ & 0.84 \\
\hline 30 to 120 & $y=608.27-0.1796 x$ & 0.95 & $y=533.68-0.0548 x$ & 0.85 & $y=524.67-0.057 x$ & 0.94 \\
\hline 60 to 180 & $y=601.43-0.1095 x$ & 0.99 & $y=530.42-0.0225 x$ & 0.98 & $y=522.3-0.0327 x$ & 0.98 \\
\hline 120 to 240 & $y=599.94-0.1017 x$ & 0.99 & - & - & - & - \\
\hline 180 to 300 & $y=601.41-0.1078 x$ & 0.99 & - & - & - & - \\
\hline 240 to 360 & $y=595.63-0.0861 x$ & 0.99 & - & - & - & - \\
\hline 300 to 420 & $y=583.12-0.048 x$ & 0.93 & - & - & - & - \\
\hline \multirow[t]{2}{*}{360 to 480} & $y=574.52-0.0266 x$ & 0.99 & - & - & - & - \\
\hline & \multicolumn{6}{|c|}{ Expanded clay } \\
\hline 15 to 60 & $y=697.94-0.5299 x$ & 0.88 & $y=655.90-0.5201 x$ & 0.65 & $y=630.21-0.1069 x$ & 0.83 \\
\hline 30 to 120 & $y=681.99-0.2055 x$ & 0.96 & $y=631.18-0.0407 x$ & 0.89 & $y=626.31-0.0279 x$ & 0.92 \\
\hline 60 to 180 & $y=674.14-0.1203 x$ & 0.96 & $y=629.14-0.0205 x$ & 0.99 & $y=625.47-0.0203 x$ & 0.99 \\
\hline 120 to 240 & $y=671.11-0.1049 x$ & 0.98 & - & - & - & - \\
\hline 180 to 300 & $y=670.35-0.0982 x$ & 0.96 & - & - & - & - \\
\hline 240 to 360 & $y=657.82-0.0527 x$ & 0.98 & - & - & - & - \\
\hline 300 to 420 & $y=659.18-0.0576 x$ & 0.98 & - & - & - & - \\
\hline
\end{tabular}

${ }^{*}$ In bold, the equations and determination coefficients for the centrifugation times required to extract all available water at a given voltage. 
For the carbonized rice husk and expanded clay materials, the time needed for centrifugation showed the same behavior for Sphagnum peat (Table 1). In contrast, for coconut powder and expanded vermiculite, adjustments were obtained between 60 and $180 \mathrm{~min}$ for three angular speeds equivalent to 10,50 , and $100 \mathrm{hPa}$ (Table 1 ).

The variation in the centrifugation time is due to the size variability and arrangement of particles of the substrates. Consequently, it is not possible to reach a single centrifugation time for all materials. However, the analyses carried out in this study allow the use of this method to determine the WRC of various materials used as substrates. Therefore, linear regressions are adjusted between three subsequent weighing events when the operator is performing the centrifugation, considering the moisture balance in the sample when the determination coefficient stipulated as appropriate is reached.

\section{Comparison of the analysis methods}

The WRC graphs obtained from the CEN-EN13041, the Büchner funnel and the sample centrifugation methods indicate that the results for all materials assessed are parallel between the three methods of analysis, except for expanded clay (Figure 3E). For Sphagnum peat (Figure 3A) and coconut powder (Figure $3 \mathrm{~B}$ ), the results were higher in the CEN-EN13041 method due to double saturation and pre-tensioning at $50 \mathrm{hPa}$ of the European method, which increased the initial water content of the samples. This may be because most organic components used as substrates, such as Sphagnum peat and coconut powder, have internal microporosity. Further, hydrophobicity impairs its saturation when dry in the case of Sphagnum peat (Raviv et al., 2004; Vence, 2012). For this reason, double saturation, which means saturating the material, subjecting it to tension at $50 \mathrm{hPa}$, and then saturating it again, acts by promoting greater water entry into the micropores, ensuring total saturation of the materials.

Regarding carbonized rice husks (Figure 3C) and expanded vermiculite (Figure 3D), the results obtained with centrifugation are similar to those obtained by the methods CEN-EN13041 and Büchner funnel. However, for expanded clay, the WRC values from the European method were higher than from the method of centrifuging samples and the funnel method (Figure 3E), because the tension applied in these analysis systems (CEN-EN13041 and Büchner funnel) may be lower than in the particles of this material.

According to Martínez (2002), expanded clay is a material with stable structures and shape, presenting particles with internal pores. Thus, the centrifugal force applied to this material probably allowed water extraction from these internal pores, which was not possible with the application of the other two methods (CEN-EN13041 and Büchner funnel). For the European method, the volumetric water content was higher than the values obtained with centrifugation. In addition, the use of funnels resulted in a balance of the moisture in the samples from the tension of $10 \mathrm{hPa}$, that is, it is not possible to extract water from this material at tensions between 10 and $100 \mathrm{hPa}$. The
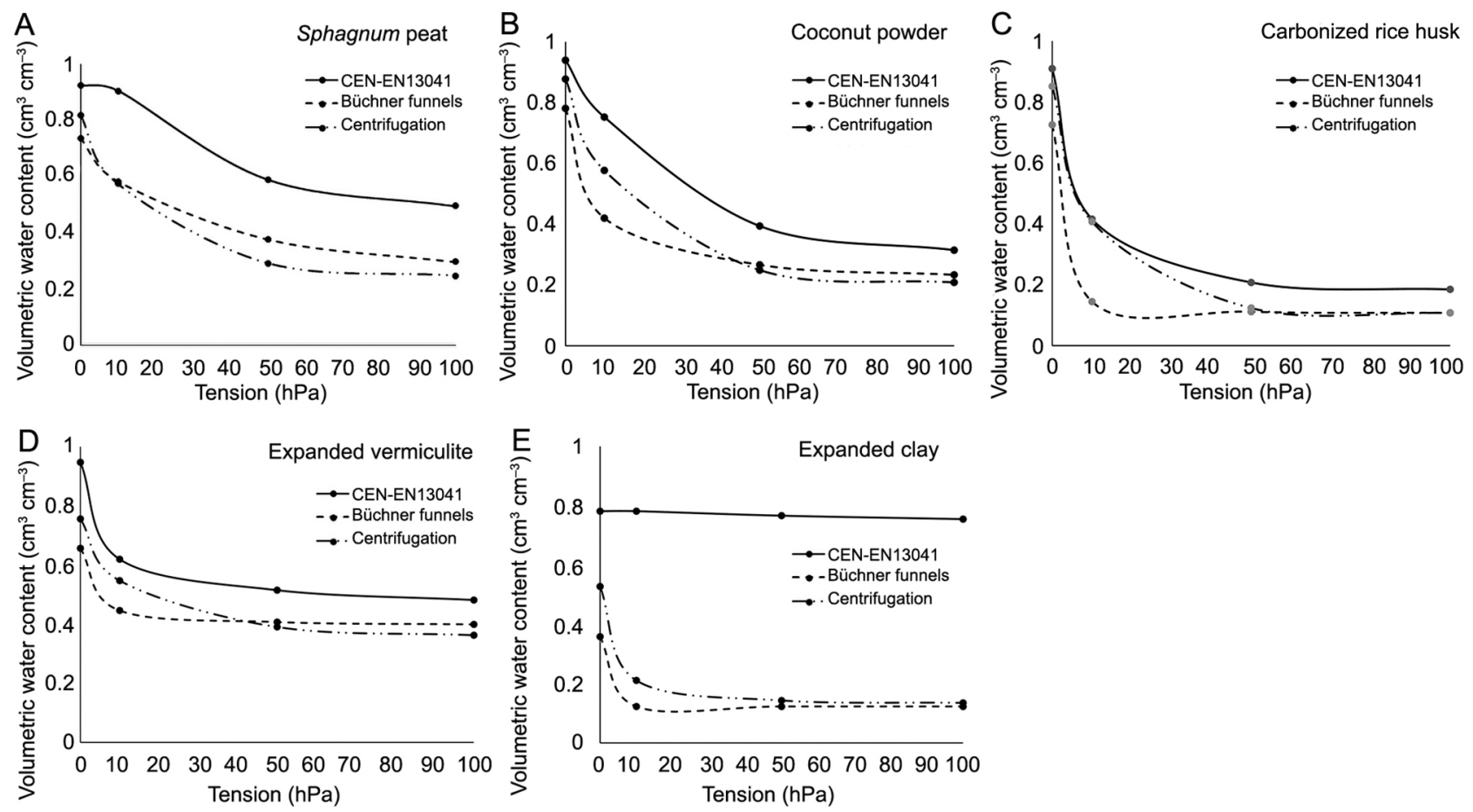

Figure 3 - Water retention curve of Sphagnum peat materials (A), coconut powder (B), carbonized rice husks (C), expanded vermiculite (D), and expanded clay (E) determined through the analysis methods CEN-EN13041, Büchner funnel, and sample centrifugation. 
volume of water remaining in the expanded clay samples after centrifugation explain this result, expressing values lower than those shown in the characterization by the method based on the European standard. Therefore, it is known that centrifugation allowed the extraction of water from this material; therefore, it was considered a more efficient method than the Büchner funnel and the CENEN13041 methods.

Considering the physical aspects involved in the methodologies tested concerning the forces exerted on water of the samples, the unusual point between the methods is how the tension is applied. This means that, in centrifugation, water is driven by a positive centrifugal force with pre-defined modules common to the methods $(10,50$, and $100 \mathrm{hPa})$, while in the others, the force that extracts the water from the samples comes from a negative pressure (tension), which only occurs in the presence of interconnected capillaries (capillarity between particles). Depending on the material, the connection of these capillaries may not occur and the applied tension is discontinued, resulting in a higher tension that provides cohesive force to water molecules, as well as in the adsorption by the substrate particles, superior in modulus, resulting in the water remaining in the sample. In other words, the outcome achieved by the centrifugation method, not by the others, is to act by removing water without the interference of factors, such as the connection of vessels. This possibly caused the failure of the CEN-EN13041 and Büchner funnel methods to determine the WRC of expanded clay, for instance.

The connection of the vessels between the material and the surface where the tension is applied may also be influenced by a third element, the voile fabric used to seal the bottom of the cylinders or the quality of the filter paper placed between the material and the tensioning surface, either in the CEN-EN13041 or in the Büchner funnel method. These elements become vulnerable points to the discontinuity of capillaries due to different physical characteristics from the material under analysis and from the surface where the stress is applied, which are essential for tension distribution in the sample. Therefore, this voile fabric or paper layer split the main connection point between the applied physical forces and the sample, which can cause discontinuity of the water film surrounding the particles, resulting in an uneven distribution of the tension exerted at the point of its application over the sample contact surface with the sand bed and/or Büchner funnel.

The centrifugation method showed consistent results in terms of water extraction for materials that are difficult to be analyzed, such as expanded clay. These materials have no negative or null values when angular velocities correspond to the tensions of 10,50 , and 100 $\mathrm{hPa}$ are applied, differently from the methods that use Büchner funnel and sand beds (CEN-EN13041) as sample tensioning systems. This reinforces the hypothesis that centrifugation of samples is a viable method to determine physical characteristics of substrates, as it provides greater reliability of the results, enabling to determine the characteristics of the air and water content of substrates that are difficult to be analyzed.

Experiments comparing several methods of analysis of parameters related to the volumetric water content corresponding to the applied voltages (10 to $100 \mathrm{hPa}$ ) show that the results are influenced by several factors, such as the effect of saturation and/ or material compaction. Moreover, the use of tension devices, the reference point from which the tensioning is considered, the initial humidity of the samples during the determination of density, the presence of overlapping cylinders, and the sample volume also affect the results (Vence, 2012; Zorzeto et al., 2014). Therefore, the results of the analyses differ from each other due to the use of a particular method, mainly, due to the handling of the samples before and during the analyses.

The method of sample centrifugation used in this work showed a positive and highly significant correlation of centrifugation with the other two methods for all materials tested at tenses 10,50 , and $100 \mathrm{hPa}$, indicating that it is a promising method to determine the volumetric water content of substrates and thus their physical characterization.

For Sphagnum peat, the correlation analysis showed a high positive correlation coefficient of the volumetric water content $\left(\mathrm{cm}^{3} \mathrm{~cm}^{3}\right)$ between the CENEN13041 method and Büchner funnel ( $\mathrm{r}=0.986)$. This result was also obtained in the correlation between the centrifugation method and the method of European standardization (Figure 4A) and with Büchner funnel (Figure 4B).

For the coconut powder material, the results were similar to Sphagnum peat, resulting in correlation coefficients with values greater than 0.98 for the volumetric water content $\left(\mathrm{cm}^{3} \mathrm{~cm}^{3}\right)$ between the three methods (CEN-EN13041, Büchner funnel, and sample centrifugation) (Figures $4 \mathrm{C}$ and $4 \mathrm{D}$ ).

The carbonized rice husk (Figures $4 \mathrm{E}$ and $4 \mathrm{~F}$ ) and expanded vermiculite (Figures $4 \mathrm{G}$ and $4 \mathrm{H}$ ) showed a significant positive correlation of the volumetric water content $\left(\mathrm{cm}^{3} \mathrm{~cm}^{3}\right)$ between the European method (CEN-EN13041) and Büchner funnel, with correlation coefficients of 0.989 and 0.946 , respectively. These two methods considered as standard in this experiment (Büchner funnel and CEN-EN13041) were positively correlated with the values obtained from centrifuging the samples at 10,50 , and $100 \mathrm{hPa}$, with a correlation coefficient of 0.989 (Figure 4E) and 0.915 (Figure 4G) between the European standard and sample centrifugation or the carbonized rice husk and expanded vermiculite materials, respectively. While between the funnels and centrifugation, the correlation coefficient values were 0.982 for the carbonized rice husk (Figure $4 \mathrm{~F}$ ) and 0.947 (Figure $4 \mathrm{H}$ ) for the expanded vermiculite.

As for expanded clay (Figures $4 \mathrm{I}$ and $4 \mathrm{~J}$ ), the correlation between centrifugation and CEN-EN13041 was significantly positive, but with a correlation 

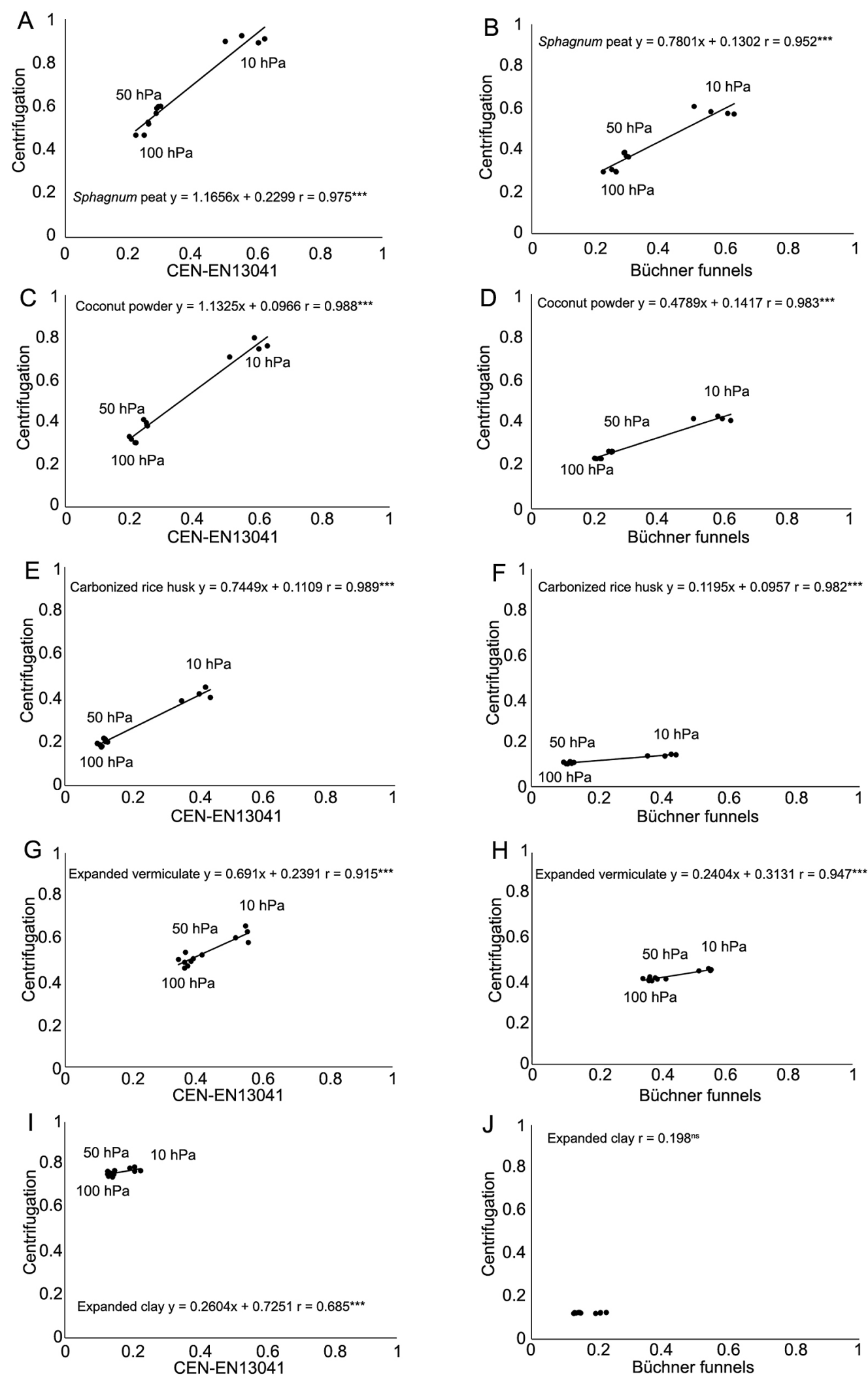

Figure 4 - Correlation of the volumetric water content $\left(\mathrm{cm}^{3} \mathrm{~cm}^{-3}\right)$ between centrifugation and CEN-EN13041 and centrifugation and Büchner funnel at 10,50, and $100 \mathrm{hPa}$, of the Sphagnum peat materials (A, B), coconut powder (C, D), carbonized rice husk (E, F), expanded vermiculite $(\mathrm{G}, \mathrm{H})$, and expanded clay (I, J). ${ }^{*} p<0.05 ;{ }^{\star \star \star}{ }^{*} p<0.001 ; \mathrm{ns}=$ not significant. 
coefficient of 0.685 (Figure 4I), lower than that found for the other materials. However, no significant correlation was found between centrifugation and the funnels (Figure 4J), nor between the funnel and the CEN-EN13041 method.

The correlation between the methods indicates by definition a close association between the results obtained with sample centrifugation and with the funnel and the CEN-EN13041, except for expanded clay. The lower correlation coefficient for expanded clay between the European method and centrifugation and the fact that the volumetric water content obtained with the funnel is not correlated with those verified in centrifugation are possibly due to the high tension inside the particles of this material, impairing water extraction at a tension lower than or equal to $100 \mathrm{hPa}$.

In addition, the variability of the results obtained from the three methods could be considered low based on the coefficient of variation data, which allows determining the volumetric water content of these materials through the centrifugation of samples.

The characterization of the physical properties displayed significant differences among the methods for materials obtained from the volumetric water content data at $0,10,50$, and $100 \mathrm{hPa}$ by the CEN-EN13041 method, by the Büchner funnel method, and by the sample centrifugation method.

The comparison between WRC data from tensioning at $10 \mathrm{~cm}$ of water column $(10 \mathrm{hPa})$ showed a significant difference between the methods, as the means were higher in comparison to the funnel and centrifugation method in the determination by the CEN-EN13041 method, except for carbonized rice husks (Table 2). This result is related to the initial treatment of the samples, that is, pre-tensioning at $50 \mathrm{hPa}$ and double saturation allowed the complete saturation of materials.

The mean values of total porosity were higher when obtained through the European method (CEN-EN13041) compared to the methods of Büchner funnel and sample centrifugation (Table 2). This is because total porosity is obtained from an indirect method using a formula that relates the dry density to the particle density, calculated from organic matter values obtained by incineration, which implies that the material loses all its original structure. Thus, all pores are counted, reaching the real porosity values of these materials show, in contrast to values from direct methods based on the concept of defining total porosity as the volumetric water content of the substrate at $0 \mathrm{hPa}$, that is, the water volume that occupies the pores when the sample is saturated.

In this context, the lower values of aeration space observed for the CEN-EN13041 method (Table 2) are explained by the high WRC at $10 \mathrm{hPa}$ that these materials exhibited in this method. This is because the formula to calculate aeration space is based on the difference between total porosity and WRC.

The differences observed in the results of total porosity according to the methods of analysis are directly attributed to the values of the relationship between air and water of the materials, since the total porosity corresponds to the volume percentage of the space not occupied by the solid phase of the samples, that is, by the proportion of air and water. Therefore, the results for water availability parameters (available water, easily available water, buffering water, and remaining water) showed variation between the methods of analysis for each material, regardless of the parameter analyzed (Table 3).

The variations obtained in the water availability parameters between the methods also result from the lower WRC that the materials showed when analyzed with the funnel and centrifugation methods. In these methods, double saturation and pre-tensioning of the samples are not used prior to the analysis. These underestimated values occur because of incomplete saturation of materials, that is, when the materials are not fully saturated, they may not really express the water amount that they can retain and make available to the plants.

Table 2 - Water holding capacity at $10 \mathrm{hPa}$, total porosity and aeration space of Sphagnum peat (SP), coconut powder (CP), carbonized rice husk $(\mathrm{CRH})$, expanded vermiculite (EV), and expanded clay (EC) according to the method of analysis.

\begin{tabular}{|c|c|c|c|c|c|c|}
\hline \multirow{2}{*}{ Parameters } & \multirow{2}{*}{ Method } & \multicolumn{4}{|c|}{ Substrates } & \multirow[b]{2}{*}{ EC } \\
\hline & & $\mathrm{SP}$ & $\mathrm{CP}$ & $\mathrm{CHR}$ & EV & \\
\hline \multirow{4}{*}{ Water holding capacity at $10 \mathrm{hPa}\left(\mathrm{cm}^{3} \mathrm{~cm}^{3}\right)$} & CEN-EN13041 & $0.91 \mathrm{a}$ & $0.75 \mathrm{a}$ & $0.41 \mathrm{a}$ & $0.62 \mathrm{a}$ & $0.78 \mathrm{a}$ \\
\hline & Büchner funnels & $0.59 \mathrm{~b}$ & $0.42 \mathrm{c}$ & $0.15 b$ & $0.45 c$ & $0.12 \mathrm{c}$ \\
\hline & Centrifugation & $0.57 \mathrm{~b}$ & $0.58 b$ & $0.41 \mathrm{a}$ & $0.55 b$ & $0.22 b$ \\
\hline & p-value & ${ }^{*}$ & $\star * *$ & ${ }^{* * *}$ & $\star * \star$ & ${ }^{* * *}$ \\
\hline \multirow{4}{*}{ Total porosity $\left(\mathrm{cm}^{3} \mathrm{~cm}^{3}\right)$} & CEN-EN13041 & $0.93 a$ & $0.94 \mathrm{a}$ & $0.90 \mathrm{a}$ & $0.95 a$ & $0.78 \mathrm{a}$ \\
\hline & Büchner funnels & $0.74 \mathrm{c}$ & $0.78 \mathrm{c}$ & $0.73 c$ & $0.66 \mathrm{c}$ & $0.36 \mathrm{c}$ \\
\hline & Centrifugation & $0.82 \mathrm{~b}$ & $0.88 b$ & $0.85 b$ & $0.76 \mathrm{~b}$ & $0.54 b$ \\
\hline & p-value & $* * *$ & $* * *$ & ** & ** & $* * *$ \\
\hline \multirow{4}{*}{ Aeration space $\left(\mathrm{cm}^{3} \mathrm{~cm}^{3}\right)$} & CEN-EN13041 & $0.02 c$ & $0.19 c$ & $0.49 b$ & $0.33 a$ & $0.00 \mathrm{c}$ \\
\hline & Büchner funnels & $0.15 b$ & $0.36 \mathrm{a}$ & $0.58 \mathrm{a}$ & $0.21 \mathrm{~b}$ & $0.24 b$ \\
\hline & Centrifugation & $0.25 \mathrm{a}$ & $0.30 \mathrm{~b}$ & $0.44 b$ & $0.21 b$ & $0.32 \mathrm{a}$ \\
\hline & $p$-value & $* * *$ & $\star \star *$ & 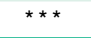 & * & 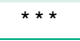 \\
\hline
\end{tabular}

${ }^{*} p<0.05 ;{ }^{* *} p<0.01$ and ${ }^{* * *} p<0.001$ by analysis of variance (ANOVA), and for total porosity in the carbonized rice husk and vermiculite, aeration space in the vermiculite, and water retention capacity in the Sphagnum peat used the Kruskal-Wallis test. Means followed by the same letter in the column do not differ statistically by Fisher's LSD (Least Significant Difference) test. 
Table 3 - Available water, readily available water, buffering water, and remaining water of Sphagnum peat materials (SP), coconut powder (CP), carbonized rice husks (CRH), expanded vermiculite (EV), and expanded clay (EC) in relation to the analysis method.

\begin{tabular}{|c|c|c|c|c|c|c|}
\hline \multirow{2}{*}{ Parameters } & \multirow{2}{*}{ Method } & \multicolumn{5}{|c|}{ Substrates } \\
\hline & & $\mathrm{SP}$ & $\mathrm{CP}$ & $\mathrm{CRH}$ & EV & EC \\
\hline \multirow{4}{*}{ Available water $\left(\mathrm{cm}^{3} \mathrm{~cm}^{3}\right)$} & CEN-EN13041 & $0.41 \mathrm{a}$ & $0.44 a$ & $0.23 b$ & $0.14 b$ & $0.03 \mathrm{~b}$ \\
\hline & Büchner funnels & $0.29 \mathrm{~b}$ & $0.19 b$ & $0.04 \mathrm{c}$ & $0.05 \mathrm{c}$ & $0.00 c$ \\
\hline & Centrifugation & $0.32 b$ & $0.37 \mathrm{a}$ & $0.30 \mathrm{a}$ & $0.19 a$ & $0.08 a$ \\
\hline & $p$-value & ${ }^{* *}$ & ${ }^{* * *}$ & *** & ${ }^{* * *}$ & ** \\
\hline \multirow{4}{*}{ Readily available water $\left(\mathrm{cm}^{3} \mathrm{~cm}^{3}\right)$} & CEN-EN13041 & $0.32 \mathrm{a}$ & $0.36 \mathrm{a}$ & $0.21 \mathrm{~b}$ & $0.11 \mathrm{~b}$ & $0.02 b$ \\
\hline & Büchner funnels & $0.20 \mathrm{~b}$ & $0.16 \mathrm{~b}$ & $0.04 \mathrm{c}$ & $0.05 \mathrm{c}$ & $0.00 c$ \\
\hline & Centrifugation & $0.28 a$ & $0.33 a$ & $0.28 a$ & $0.16 a$ & $0.07 a$ \\
\hline & $p$-value & ${ }^{* *}$ & $* * *$ & $* * *$ & ${ }^{* *}$ & ${ }^{* *}$ \\
\hline \multirow{4}{*}{ Buffering water $\left(\mathrm{cm}^{3} \mathrm{~cm}^{3}\right)$} & CEN-EN13041 & $0.09 a$ & $0.08 \mathrm{a}$ & $0.022 a$ & $0.03 a$ & $0.01 a$ \\
\hline & Büchner funnels & $0.08 \mathrm{a}$ & $0.03 c$ & $0.004 \mathrm{c}$ & $0.008 b$ & $0.00 \mathrm{~b}$ \\
\hline & Centrifugation & $0.04 b$ & $0.04 \mathrm{~b}$ & $0.016 b$ & $0.03 a$ & $0.01 \mathrm{a}$ \\
\hline & p-value & ${ }^{* *}$ & $* *$ & $\star * *$ & * & ${ }^{*}$ \\
\hline \multirow{4}{*}{ Remaining water $\left(\mathrm{cm}^{3} \mathrm{~cm}^{3}\right)$} & CEN-EN13041 & $0.50 a$ & $0.31 \mathrm{a}$ & $0.18 a$ & $0.48 a$ & $0.75 a$ \\
\hline & Büchner funnels & $0.30 \mathrm{~b}$ & $0.23 b$ & $0.11 b$ & $0.40 \mathrm{~b}$ & $0.12 c$ \\
\hline & Centrifugation & $0.25 \mathrm{c}$ & $0.21 \mathrm{c}$ & $0.11 b$ & $0.36 \mathrm{c}$ & $0.14 b$ \\
\hline & $p$-value & $* * *$ & ** & $* * *$ & $\star \star \star *$ & $* * *$ \\
\hline
\end{tabular}

${ }^{\star} p<0.05 ;{ }^{* *} p<0.01$ and ${ }^{* * *} p<0.001$ by analysis of variance (ANOVA), and for water available in expanded clay, water easily available in vermiculite and expanded clay, buffering water in coconut powder, vermiculite, and expanded clay, and water remaining in the coconut powder, the Kruskal-Wallis test was used. Means followed by the same letter in the column do not differ statistically by Fisher's LSD (Least Significant Difference) test.

In this sense, the main differences observed in the parameters of physical characterization of substrates according to the methods of analysis resulted from the initial treatment of the samples, among other factors. Studies show the results of changes in the number of solids per sample in the total porosity, in WRC, in the accommodation of the particles, and the distribution of the pore size due to the initial humidity that the samples presented prior to the analysis (Fonteno, 1993; Fermino and Kämpf, 2005; Vence, 2012; Zorzeto et al., 2014). However, initial sample handling affect materials differently, depending on the type and size of pores and the size and compressibility of particles (Vence, 2012).

According to Zorzeto et al. (2014), differences in determining the WRC in the methods of analysis assessed are due to the initial treatment of the sample, among other factors. Likewise, Vence (2012) found differences in the physical characterization of commercial substrates according to the methods used, which is due to the initial treatment of samples, that is, sample initial humidity subjected to characterization.

Moreover, the values of variables obtained from the funnel method may have been underestimated, in some cases. This hypothesis is based on the possibility that the particles were accommodated (self-compacting) after successive re-saturation between each change in the water column point, that is, the sample volume inside the analysis cylinders is changed after subjected to different tensions. Thus, the final volume reduces compared to the initial volume under saturation conditions, which is not considered in the calculation to obtain these parameters. This effect does not occur in the European method (CENEN13041). According to Vence (2012), the use of the double ring during saturation with the removal of the upper ring after tensioning at $10 \mathrm{hPa}$ allows the samples to naturally undergo the self-compaction process during these processes thus preventing the sample volume from changing at subsequent stresses (50 and $100 \mathrm{hPa}$ ).

Further experiments are needed to propose methods that provide reliable results and with greater repeatability, because of differences in the results of the analyses, mainly due to the initial treatment of the samples and limitations of the methods currently available for the physical characterization of substrates, such as the methods CEN-EN13041 and Büchner funnel,.

According to Fonteno (1993), a method to characterize substrates should be based on equipment availability, nature of the material to be analyzed, type of sample available, knowledge and skill of the operator, and purpose of the measurements. In addition, the results obtained through different methods vary depending on the materials used as substrates; thus, requiring methods that provide reliable results, regardless of the type of the material analyzed, and that are also easy to carry out.

The method of sample centrifugation provides results more readily available, besides greater reliability and repeatability of the results, as it reduces time required to determine the complete WRC of substrates. The CEN-EN13041 method required 10 days, while the Büchner funnel method needed 11 days. Nevertheless, sample centrifugation required approximately five days to determine these parameters, reducing by half the time necessary to obtain a complete substrate analysis report and improving routine procedures of laboratory analysis.

An experiment on five different types of soil representatives of the Cerrado Biome determined the WRC by applying centrifugation period greater than $80 \mathrm{~min}$ at each angular velocity, where centrifugation periods below equilibrium altered the $\mathrm{WRC}$, particularly 
affecting the humidity values at the highest tensions (Silva and Azevedo, 2001).

Sample centrifugation also allows determining the WRC of substrates with greater control over the environmental variables. One of the main limitations of the method of Büchner funnel and sand beds is the lack of temperature and relative humidity control in the environment where the analysis is executed, which affects the process, mainly due to the excessive time in which the samples are subjected to tensioning. This can prevent calculation of the water mass evaporated from the samples during the days of analysis, resulting in errors and reducing repeatability, since the environment can vary from one analysis to another, even in the same laboratory.

The method of samples centrifugation allow overcoming challenges of the Büchner funnel and sand bed methods (CEN-EN13041). Challenges involve limitations in the time required to obtain results, possible break of the water column, discontinuity of the water film between the surface where the tension and the material under analysis are applied, difficulty in determining the balance between the tension applied and the water retained in the substrate sample.

\section{Conclusion}

The results confirmed the experiment hypothesis, as sample centrifugation presented as a promising method to analyze the physical characteristics of substrates that determine the parameters of the WRC. In addition to ensuring the tension force, centrifugation acts on the entire sample to determine the substrate WRC, generating results with reliability and repeatability, also reducing the analysis time thus optimizing routine laboratory procedures.

\section{Acknowledgments}

The authors would like to thank Atelene Normann Kämpf for the partnership, teaching and support in all phases of completion of this study. To Carla Andrea Delatorre for the availability of the Laboratory of the Department of Crop Plants of the Faculty of Agronomy of the Federal University of Rio Grande do Sul. The authors also thank the Department of Horticulture and Silviculture of the Faculty of Agronomy of the Federal University of Rio Grande do Sul, the Laboratory of Substrates of the Cátedra de Jardinería, Faculty of Agronomy, University of Buenos Aires, the Brazilian National Council for Scientific and Technological Development (CNPq), and the Research Support Foundation of the State of Rio Grande do Sul (FAPERGS).

\section{Authors' Contributions}

Conceptualization: Avrella, E.D.; Fior, C.S. Data acquisition: Avrella, E.D.; Vence, L.B. Data analysis: Avrella, E.D.; Vence, L.B. Design of methodology:
Avrella, E.D.; Fior, C.S.; Vence, L.B. Writing and editing: Avrella, E.D.; Fior, C.S.; Paim, L.P.; Emer, A.A.

\section{References}

Bunt, A.C. 1983. Physical properties of mixtures of peats and minerals of different particles size and bulk density for potting substrates. Acta Horticulturae 150: 143-153.

Caron, J.; Elrick, D.E.; Beeson, R.; Boudreau, J. 2005. Defining critical capillary rise properties for growing media in nurseries. Soil Science Society of America Journal 69: 794-806.

Comité Europeén de Normalisation [CEN]. 1999. EN 13041 - Soil Improvers and Growing Media: Determination of Physical Properties - Dry Bulk Density, Air Volume, Water Volume, Shrinkage Value and Total Pore Space. Comité Europeén de Normalisation, Bruxelles, Belgium.

De Boodt, M.; Verdonck, O. 1972. The physical properties of the substrates in horticulture. Acta Horticulturae 26: 37-44.

Fermino, M.H.; Kämpf, A.N. 2005. Considerations about the packing density of growing media prepared under increasing levels of humidity. Acta Horticulturae 697: 147-151.

Fonteno, W.C. 1993. Problems \& considerations in determining physical properties of horticultural substrates. Substrates in horticulture. Acta Horticulturae 342: 197-204.

Fonteno, W.C.; Cassel, D.K.; Larson, R.A. 1981. Physical properties of three container media and their effect on poinsettia growth. Journal of the American Society for Horticultural Science 106: 736-741.

Martínez, P.F. 2002. Handling substrates for horticulture. p. 5376. In: Milner, L.D.; Furlani, A.M.C.; Bataglia, O.C.; Abreu, M.F.; Abreu, C.A.; Furlani, P.R.; Quaggio, J.A.; Minami, K., eds. Characterization, management and quality of substrates for plant production. Instituto Agronômico, Campinas, SP, Brazil (in Portuguese, with abstract in English).

Raviv, M.; Wallach, R.; Blom, T.J. 2004. The effect of physical properties of soilless media on plant performance: a review. Acta Horticulturae 644: 251-259.

Silva, E.M.; Azevedo, J.A. 2001. Centrifugation Period Suitable for Lifting the Water Retention Curve in Cerrado Biome Soils. Embrapa Cerrados, Planaltina, DF, Brazil. (Boletim de Pesquisa e Desenvolvimento, 8) (in Portuguese, with abstract in English).

Vence, L.B. 2012. Methods for determining parameters that estimate the availability of water-air in plant substrates and its relationship with the plant response. Dissertation - Facultad de Agronomía, Universidad de Buenos Aires, Buenos Aires (in Spanish, with abstract in English).

Verdonck, O.; Cappaert, I.M.; De Boodt, M. 1978. Physical characterization of horticultural substrates. Acta Horticulturae 82: 191-200.

Wallach, R.; Silva, F.; Chen, Y. 1992. Hydraulic characteristics of tuff (scoria) used as a container medium. Journal of the American Society for Horticultural Science 117: 415-421.

Wever, G.; Van Winkel, A. 2004. Interlaboratory study CENMethods for the analysis of growing media and soil improvers. Acta Horticulturae 644: 597-601.

Zorzeto, T.Q.; Dechen, S.C.F.; Abreu, M.F.; Fernandes Júnior, F. 2014. Physical characterization of substrates for plants. Bragantia 73: 300-311 (in Portuguese, with abstract in English). 